is growth exponential? - Yes. Microbiology 144, 263-265.

3. Mitchison, J.M. (1961). The growth of single cells. III. Streptococcus faecalis. Exp Cell Res 22, 208-225.

4. Mitchison, J.M (1989). Cell cycle growth and periodicities. In Molecular Biology of the Fission Yeast, pp. 205-242. Edited by A. Nasim, P. Young \& B.F.

Johnson. San Diego: Academic Press.

5. Prescott, D.M. (1955). Relations between cell growth and cell division. I. Reduced weight, cell volume, protein content and nuclear volume of Amoeba proteus from division to division. Exp Cell Res 9, 328-337.

6. Sveiczer, A., Novak, B. \& Mitchison, J.M. (1996). The size control of fission yeast revisited. $J$ Cell Sci 109, 2947-2957.

\section{Further correspondence}

The central question asked here is "Do the data that were used to show two linear segments during the first $80 \%$ of the division cycle also support exponential growth?" I can only reiterate, despite the assertion by J. M. Mitchison, A. Sveiczer \& B. Novak (above) that my Fig. 1 definitely shows that length growth is exponential and not bilinear. Res ipsa loquitur. The data in Fig. 1 of J. M. Mitchison, A. Sveiczer \& B. Novak (above) are difficult to analyse as the smoothing function ('rsmooth') seems to have obliterated any observed variations such as those at $70-75 \mathrm{~min}$ and $90-95 \mathrm{~min}$ in the rate graph. In any case, the raw data of their Fig. 1 appear compatible with an exponential function and would show this if plotted using semi-logarithmic coordinates. The variability of the data (although no error bars are shown) blurs the distinction between bilinear or exponential growth.

\section{Stephen Cooper}

The 'central question' for Cooper must surely be whether there is a simple exponential growth law without RCPs for the whole cell cycle. This is clearly not so, since there are RCPs at the beginning and end of the constant length period. The third RCP during the growth period is conspicuous in wee 1 mutants (ignored by Cooper, though he has had the data), but less so in wild-type cells because the change in rate is smaller. In his supplementary correspondence, Cooper says that his Fig. 1 "definitely shows that length growth is exponential and not bilinear". This is highly misleading, since Fig. 1 only shows the exponential model and not the bilinear model, which would be extremely similar to an exponential on this semi-logarithmic plot. Indeed he finds that the numerical distinctions ( $r^{2}$ values) between the different models are negligible. He has therefore to rely on the very weak argument that an exponential is preferable because it has fewer parameters and is simpler. This pre-judges the issue between simplistic models and the real life of cells. He ignores the fact that we have used a much more sensitive method which is equivalent to sequential differentiation in our Fig. 1, which shows a cell with a clear bilinear pattern. Smoothing processes have to be used with care since they obviously reduce variations but they are needed with 'noisy' data such as raw cell lengths. What Cooper does not mention is that our data used in his Fig. 1 had been smoothed by the same process used in our Fig. 1. Error bars, incident:ally, are not appropriate in this work since individual cells grow at different rates and have different RCPs.

J. M. Mitchison, A. Sveiczer and B. Novak 